\title{
La burbuja inmobiliaria de la "década prodigiosa” en España (1997-2007): políticas neoliberales, consecuencias territoriales e inmunodeficiencia social. Reflexiones para evitar su reproducción
}

Pedro Górgolas. Universidad de Sevilla, Sevilla, España.

RESUMEN | El presente artículo surge en respuesta al desconcierto causado por los indicios que apuntan a la posible incubación de una nueva burbuja inmobiliaria en España, que podría reproducir, a medio plazo, la sintomatología característica de la "década prodigiosa del urbanismo expansivo" (1997-2007). Verificar tales indicios, exponer las causas que alentaron los excesos territoriales de aquellos años, apuntar los principios de política económica aplicados y constatar que la herencia territorial recibida es consecuencia de un planeamiento urbano cautivo de los intereses del mercado inmobiliario, conforman el marco discursivo previo al abordaje del tema central del artículo: realizar una taxonomía de la actitud inmunodeficiente mostrada por la sociedad espańola ante tales excesos, toda vez que, para liberarnos de nuestra dependencia del capitalismo inmobiliario, se precisa una mutación sustancial de esta conducta patógena que impulse el pensamiento crítico y la reflexividad social.

PALABRAS CLAVE $\mid$ mercado inmobiliario, urbanización, transformaciones socioterritoriales.

ABSTRACT | The article's subject matter arises in response to the bewilderment caused by the indications that point to the possible incubation of a new real estate bubble in Spain that could reproduce, in the medium term, the characteristic symptomatology of the "prodigious decade of expansive urbanism" (1997-2007). Verifying such indications, exposing the causes that have allowed the territorial excesses of those years to occur, pointing out the applied principles of economic policy and verifying that the territorial inheritance received carries an urban planning captive of the interests of the real estate market, conform the discursive framework prior to the approach of the central theme of the article: to conduct a taxonomy of the immunodeficient attitude shown by the Spanish society in light of such excesses, as, to liberate us from our dependence on real estate capitalism, a substantial mutation of this pathogenic conduct is needed to drive critical thinking and social reflectiveness.

KEYWORDs | real estate market, urbanization, socio-territorial transformations. 


\section{Objetivos, contenido y metodología del artículo}

La economía española muestra indicios de una recuperación que apunta a la posible gestación de una nueva burbuja especulativa que perpetuaría su indeleble actitud servil hacia el capitalismo inmobiliario, trayectoria inercial que se viene reproduciendo secuencial y sistemáticamente desde el tardofranquismo. Ante esta hipótesis, el objetivo central del artículo es impedir que las causas que impulsaron la burbuja sufrida en España durante la denominada "década prodigiosa" (1997-2007) ${ }^{1}$ caigan en el olvido para, así, sortear la repetición de sus dramáticas consecuencias socioterritoriales. Esta evitación precisa, indefectiblemente, corregir la condescendencia de la ciudadanía con los excesos cometidos durante aquellos ańos. Es un hecho incontestable que sin su consentimiento -cuando no impulso acrítico-, sus efectos se hubiesen visto sustancialmente atemperados.

Efectivamente, en este periodo, la sociedad espańola adoleció del denominado "síndrome de inmunodeficiencia social", concepto acuñado por el filósofo español José Antonio Marina para significar las disfuncionalidades que afectan a una sociedad cuando, carente de energía ética, se muestra incapaz de combatir y neutralizar agentes nocivos (Marina, 2012). A consecuencia de esta conducta apática, la capacidad crítica de los españoles se inhibió para consentir con epifenómenos característicos de las políticas públicas desarrolladas en dicha década: fomento del urbanismo neoliberal y especulación del suelo, incentivación del endeudamiento privado para ampliar artificialmente la demanda inmobiliaria o prácticas corruptas que, una vez aflorada la crisis, han quebrado la confianza en nuestro sistema institucional.

La interiorización, por parte de la ciudadanía, de la necesidad de reparar esta sintomatología carencial requiere conocer, en su verdadera dimensión, el relato de lo sucedido. Y ello implica adquirir consciencia de los fundamentos económicos que indujeron el frenesí inmobiliario de aquellos años, constatar la metástasis territorial ocasionada y evaluar los motivos de su beneplácito social. Por ello, en el cuerpo principal del artículo se desarrolla una exploración causal donde:

a. En primer lugar, se explicitan los principios de la política económica de sesgo neoliberal desencadenantes del expansivo protocolo de artificialización territorial de la última burbuja inmobiliaria, vehiculizado a través de un planeamiento urbano cautivo de los intereses del mercado inmobiliario. Este inventario axiológico, y su correlato territorial, se introducen con una exposición previa de datos e indicadores que muestran las singularidades, en relación con otros países del mundo desarrollado, de esta fase alcista de la economía espańola.

b. A continuación, se exhibe el diagnóstico de las pulsiones que alentaron la aceptación social de lo acontecido durante dicho periodo. Para entender esta actitud patógena hay que tener presente que, en toda sociedad, el comportamiento de sus individuos está condicionado por la red de significados compartidos expresiva del contexto cultural de cada periodo histórico, que, a su vez, trae causa en su trayectoria dependiente (path dependence). En este sentido, hay un amplio

1 Este periodo discurre entre la llegada al poder del Partido Conservador a mediados de 1996 y la quiebra del sistema financiero mundial a finales de 2007. 
consenso disciplinar en aceptar la existencia de una vinculación siamesa entre la condición líquida de la sociedad contemporánea y el neoliberalismo como teoría político-económica hegemónica desde finales de los años setenta del siglo pasado (Bauman, 2004; Méndez, 2017; Theodore, Peck \& Brenner, 2009; Vásquez Rocca, 2008).

Así, la metodología empleada para realizar este diagnóstico entabla una dialéctica discursiva entre, por un lado, manifestaciones paradigmáticas de la conducta socialmente receptiva respecto de las políticas desplegadas (deslegitimación del planeamiento como instrumento de ordenación territorial garante del interés colectivo, aceptación de la suburbanización dispersa y tolerancia con la corrupción urbanística); y por otro, características sociales (ética consumista, individualismo exacerbado, insensibilidad moral) consustanciales a estos tiempos líquidos (Bauman, 2004, 2006; Bauman \& Donskis, 2015).

Expuestos los rasgos propios de la última burbuja inmobiliaria, y ante la aguda recesión causada por su repentina deflagración (Torres, 2010, pp. 93-122), en el epígrafe final se advierte sobre el peligro que supone reincidir en errores pasados, situación indiciaria a la que apunta la hoja de ruta adoptada en España para emprender la recuperación económica. Para fundamentar esta alerta, se aportan cifras destiladas de fuentes estadísticas y opiniones expertas que parecen confirmar el pronóstico burbujista antes reseńado. El artículo concluye significando la necesidad de reconducir esta tendencia inercial mediante una construcción social resiliente que cauterice el síndrome inmunodeficiente de la sociedad española, al objeto de oxigenar el urbanismo poscrisis y reconducir, en términos de sostenibilidad, la herencia territorial recibida (Górgolas, 2016). Ello debería coadyuvar a iniciar una senda de innovación que libere nuestro país de su histórica dependencia de la actividad inmobiliaria.

\section{Breve recapitulación sobre las causas económicas y las consecuencias territoriales de la burbuja inmobiliaria de la “década prodigiosa” (1997-2007)}

La última burbuja inmobiliaria no es un acontecimiento aislado en la historia reciente de España. En los últimos cincuenta años, su crecimiento económico se ha apoyado en la secuenciación de tres booms inmobiliarios -el tardofranquista (19631973), el neodemocrático (1985-1992) y el vinculado al cambio de milenio (19972007) (Górgolas, 2017) - que indican una clara dependencia de este sector. Es cierto que el protagonismo de la dimensión inmobiliaria de la economía no es exclusivo del caso español, sino que forma parte del código genético de la revolución financiera que ha liderado las dinámicas globales de las últimas décadas (Daher, 2013). Sin embargo, el efecto acumulado de estos tres periodos y, en especial, la escala adquirida por el último de ellos, han hecho de España un ejemplo paradigmático de modelo económico abducido por el capitalismo inmobiliario (Campos, 2008, p. 19; López \& Rodríguez, 2010, pp. 188-196).

Los indicadores macroeconómicos del último ciclo alcista siguen, hoy día, provocando sorpresa y revelan su intensidad diferencial respecto del experimentado 
en el resto de naciones del primer mundo. Así, el crecimiento porcentual del pIB en esa década, a un ritmo anual medio del 4,3\%, fue superior al producido tanto en Estados Unidos como en todos los estados miembros de la Unión Europea. Destaca al respecto, como hecho sintomático, la importante contribución del sector de la construcción, que aportó un 25\% a dicho incremento (García-Montalvo, 2009, p. 81). ${ }^{2} \mathrm{Al}$ tiempo, se registraron tasas de creación de empleo -un total de siete millones, a un ritmo anual del 3\%-que resultaron inalcanzables para los principales países desarrollados (López \& Rodríguez, 2010, pp. 206-207). Al final del ciclo, la riqueza inmobiliaria espańola había superado el 600\% del PIB, frente al 260\% de Estados Unidos o el 374\% de Japón (Campos, 2008, p. 49).

En este periodo, el ritmo anual de construcción de viviendas (18 viviendas/mil habitantes) triplicó la cadencia media (5,7 viviendas/mil habitantes) de los países europeos y, por ello, el parque residencial español presenta la proporción más elevada (550 viviendas/mil habitantes) del continente (Campos, 2008, p. 48). Por su parte, el precio de la vivienda se incrementó por encima del 195\% (Rodríguez, 2017, p. 73), una revalorización sin paragón entre las más importantes economías mundiales, salvo Reino Unido (Campos, 2008, p. 29); y en cuanto al régimen de tenencia en propiedad, este alcanzó el 87\%, frente al 70\% de Estados Unidos (López \& Rodríguez, 2011, p. 10) y de la UE-28 (Eurostat, Statistic Explained).

Estos datos son denotativos, sin duda, de las peculiaridades ingénitas a la burbuja inmobiliaria que se desarrolló en España durante aquellos años. El presente epígrafe se destina a identificar sintéticamente sus atributos definitorios, al objeto de contribuir a comprender las causas que la impulsaron y certificar las secuelas territoriales provocadas. La recapitulación realizada se ha centrado en exponer: (i) los principios de política económica aplicados en España en aquellos años y (ii) una síntesis de datos indicativos del frenético proceso de artificialización territorial que se produjo gracias a la vehiculación, a través del planeamiento urbanístico, de la voracidad consumista de territorio reclamada por el mercado inmobiliario.

\section{El "neoliberalismo realmente existente" en la década prodigiosa del urbanismo español}

La crisis del capitalismo de finales de la década de los setenta del siglo xx se saldó con un profundo cambio en tres frentes: el régimen de acumulación, el modelo de regulación y las soluciones espaciales adoptadas que afectaron la lógica territorial predominante (Méndez, 2014, pp. 217-232). A pesar de ciertas tendencias generales que responden a una pauta común -protagonismo del sector inmobiliario, precarización del empleo, desmaterialización de la economía o polarización social-, el neoliberalismo económico surgido de dicha crisis ha presentado diferentes rostros en función de la forma en que se produjo su inoculación en cada nación, región o ciudad, lo cual depende de factores territorializados, como el ordenamiento jurídico-normativo en vigor, las características específicas del mercado de trabajo, la política de inversiones públicas para fomentar el desarrollo económico o el diseño

2 No debe extrañar este dato, ya que el crédito a la construcción y a las actividades inmobiliarias aumentó desde el 25\% del total en el año 2000, al 47\% en 2008 (Torres, 2010, p. 106). 
de la arquitectura del gobierno del territorio. Es lo que Theodore, Peck y Brenner (2009) denominan el "neoliberalismo realmente existente", que adquiere "arreglos espaciales diferenciados” en función de cada circunstancia local.

En el caso español, pueden significarse cuatro aspectos expresivos de las especificidades de las políticas neoliberales instrumentadas en los años de la década prodigiosa: (i) una legislación urbanística receptiva a los intereses del sector inmobiliario; (ii) la financiarización de las economías domésticas; (iii) la deriva infraestructural seguida por la política de inversiones públicas; y (iv) la creación de "máquinas de crecimiento inmobiliario".

a. La andadura legislativa del nuevo gobierno conservador surgido de las elecciones generales de 1996, se inicia con la formulación del Real Decreto-Ley 5/96, del 7 de junio, sobre "Medidas liberalizadoras en materia de suelo y de colegios profesionales", empezando una senda desreguladora de la actividad urbanística (López de Lucio, 1997) que se concretó, al año de la publicación de la Sentencia 61/97 del Tribunal Constitucional, ${ }^{3}$ en la promulgación de la Ley 6/1998 del 13 de abril, de régimen del suelo y valoraciones. El principal objetivo de la Ley era inequívoco: promover la liberalización del mercado de suelo tal y como recomendó el Informe del Tribunal de Defensa de la Competencia de 1993 y comenzó a cristalizarse en el citado Real Decreto-Ley. La principal consecuencia de la nueva orientación del marco legislativo -favorecedora de la desregulación y, por tanto, claramente alineada con las tesis neoliberales de producción de ciudad- fue la impregnación de estos principios en la formulación del planeamiento territorial y urbanístico de esa época, lo que favoreció la explosión territorial asociada al afloramiento de un tsunami inmobiliarioconstructor de intensidad desconocida hasta entonces.

b. En este periodo, el sector financiero abandona sus nichos tradicionales de actividad -la financiación a empresas y los mercados de valores- y comienza a penetrar con fuerza en el tejido social. Esta estrategia de política económica, denominada "keynesianismo del precio de activos" (López \& Rodríguez, 2010, pp. 83-129), fundamenta, en gran medida, las circunstancias especiales del boom inmobiliario acaecido en España en este periodo. En síntesis, se trata de incentivar la demanda interna facilitando el endeudamiento privado mediante una política más laxa en la concesión de créditos, con lo que se consigue drenar el ahorro familiar hacia la adquisición de productos financieros, constituyendo las hipotecas un caso paradigmático. Así, "el volumen de crédito para adquisición de viviendas se multiplicó por 5,25 entre 1992 y 2002. El aumento del crédito inmobiliario ha sido un factor fundamental en el crecimiento del endeudamiento de las familias españolas que, a finales del 2002, alcanzaba la cota del $80 \%$ de la renta bruta disponible" (García-Montalvo, 2008, p. 170). Este desmesurado aumento de la demanda se produjo, sorprendentemente, en un escenario generalizado de pérdida progresiva del poder adquisitivo de los ciudadanos. En este dato reside la verdadera perversión del mecanismo de política

3 Esta Sentencia del Tribunal Constitucional dejó sin efecto la legislación urbanística en vigor (TRLS/92) al declarar inconstitucionales las cuatro quintas partes de su articulado. 
económica ideado con la democratización financiera. El objetivo era restaurar el beneficio capitalista en un contexto caracterizado por la depresión salarial ${ }^{4}$ y el estancamiento de la tasa de beneficio de los sectores manufactureros (López \& Rodríguez, 2010, pp. 229-236).

c. En el marco de la economía keynesiana, la inversión en infraestructuras había tenido una función anticíclica, al constituirse en un potente motor de la demanda. En el marco de la política neoliberal, esta estrategia de inversión pública cambia de funcionalidad, orientándose a estimular el precio de los activos inmobiliarios (López \& Rodríguez, 2010, pp. 315-316). El impresionante volumen de dinero inyectado por Europa a nuestro país en los últimos treinta años -provenientes de los fondos estructurales movilizados con el objetivo de promover la convergencia entre los estados miembros de la UE- se destinó, preferentemente, a la construcción de grandes infraestructuras de transporte, ${ }^{5}$ transformando la situación de déficit estructural existente a mediados de los años ochenta del siglo xx, en la sobrecapacidad actual: España es el país europeo con mayor dotación de kilómetros por habitante en red ferroviaria de alta velocidad (69,5 cada millón de habitantes, el doble que en Francia y cuatro veces más que en Alemania) y red de autopistas (340 cada millón habitantes, duplicando la dotación de Francia y Alemania), y lidera también las cifras en número de aeropuertos (con un total de 48, nueve más que Alemania) (Ministerio de Fomento, Observatorio del Transporte y la Logística en España).

Esta política de inversión pública denota una estrategia, nunca declarada, orientada a incrementar exponencialmente la accesibilidad del territorio como fundamento primigenio que convoca el deseo irrefrenable de su ocupación por actividades urbanas, provocando una suerte de "isotropía localizativa" que impregnó a todas las regiones de España de un inusitado fervor inmobiliario. Ninguna unidad territorial, comarca, provincia o área metropolitana española se libró de los efectos de este "tsunami" (Fernández, 2006).

d. Sin duda, el rasgo más característico de la aplicación de los fundamentos del neoliberalismo a las políticas territoriales aplicadas en España ha sido la consideración de las ciudades como "máquinas de crecimiento" (Logan \& Molotch, 2015, pp. 157-210). Esta teoría económica descansa sobre la aplicación de políticas públicas de corte empresarial -el denominado "empresarialismo urbano"-, alimentadas por la activa disposición de los gobiernos locales a la mercantilización del territorio como estrategia prioritaria de crecimiento económico (López \& Rodríguez, 2010, pp. 341-347).

En 2006, la retribución del trabajo creció un 3,4\% mientras que los beneficios de las sociedades que cotizan en Bolsa lo hicieron por encima del 26,6\% (Torres, 2010, p. 107).

5 Entre 1985 y 2010, Espańa recibió cerca de 88.000 millones de euros netos de los fondos estructurales, destinados a financiar cerca del $50 \%$ de las grandes obras públicas ejecutadas en ese periodo (líneas de alta velocidad, autopistas y aeropuertos). Véase rtve.es, Noticias/Mundo, 12 de agosto de 2010, "Espańa ha recibido de Europa en 25 ańos más dinero que toda Europa con el Plan Marshall”. http://www.rtve.es/noticias/20100612/espana-recibido-europa-25-anos-masdinero-toda-europa-plan-marshall/335058.shtml (consulta: 12-11-2017). 
La arquitectura institucional del Estado de las Autonomías, que transfiere a las regiones espańolas las competencias en materia de vivienda, ordenación del territorio y urbanismo, ha contribuido decisivamente a impulsar estas políticas pro-growth, al otorgar la potestad decisional sobre tales cuestiones a este nivel de gobierno. Ante la generalizada identificación social de "extensión urbana" con bienestar y empleo, las políticas de incentivación de la actividad inmobiliaria cobraron en Espańa un protagonismo incuestionable, circunstancia constatable en los réditos electorales de formaciones políticas de ámbito regional y local que alentaron este proceso (los casos de Marbella, en Andalucía; la Comunidad Valenciana, la Región de Murcia o la Comunidad de Madrid, son expresivos de esta circunstancia).

La extensión a todo el territorio nacional del modelo de desarrollo económico basado en la simbiosis entre un urbanismo expansivo y la financiarización de las economías domésticas, ha resultado plenamente congruente con la formación de las "máquinas de crecimiento". En buena medida, en aquellos ańos, "el principal axioma de la ideología neoliberal fue comprendido por muchos, en Espańa, como una realidad tangible: que la libertad del mercado y la iniciativa privada constituyen la mejor garantía para el estímulo del crecimiento económico y que esta es la única y verdadera política social efectiva” (López \& Rodríguez, 2010, p. 351).

En conclusión, la burbuja desarrollada en España en los años interseculares ha devenido un laboratorio de experimentación para la puesta en práctica de las tesis neoliberales que, desde años atrás, estaban triunfando en el mundo anglosajón y se habían residenciado en la totalidad de los organismos internacionales, tanto de alcance global (Fondo Monetario Internacional, Banco Mundial, Organización Mundial del Comercio) como en la propia la Unión Europea. A resultas de esta nueva ideología dominante, la tradicional dimensión inmobiliaria de la economía espańola encontró en el sector financiero un aliado esencial para desarrollar todo su potencial. La entrada de España en el euro, la drástica reducción de los tipos de interés, una regulación fiscal favorable a la adquisición de la vivienda, la generalización del acceso a un crédito barato, una legislación urbanística más permisiva y la deriva empresarial adoptada por las corporaciones locales en sus políticas urbanas, conformaron una suerte de tormenta perfecta, de la que resultó el periodo de efervescencia inmobiliaria más intenso y duradero de la historia de España.

\section{Expansividad territorial, ciudad dispersa y planeamiento urbano}

El principal epifenómeno territorial de la situación generada por este frenesí inmobiliario es la configuración de un modelo disperso, expansivo y bulímico (Fernández, 2006; Mella, 2008), asimilable a la "lógica del melanoma cancerígeno", sintetizada en estas cuatro características: i) crecimiento rápido e incontrolado; (ii) indiferenciación de las células malignas; (iii) metástasis en diferentes lugares; e (iv) invasión y destrucción de los tejidos adyacentes (Naredo \& Montiel, 2011, p. 19).

El correlato urbanístico de esta sintomatología cancerígena es un protocolo de ocupación territorial que extiende "salpicaduras urbanas clonadas y 
monofuncionales" - caracterizadas por el reinado de las viviendas unifamiliares y los grandes contenedores comerciales y de ocio que ejercen de complemento básico para el habitante de este estallamiento urbano-, precisando para ello de una profusa y capilar red arterial que facilite este proceso de colonización fractal. Según datos del Observatorio de la Sostenibilidad en España (OSE), en el periodo 2000-2006 las superficies artificiales que más aumentaron fueron las redes viarias, ferroviarias y sus terrenos asociados (un 183\%), además de las zonas urbanas (un 123\%), "produciéndose una transformación radical del modelo de ciudad (...). La tendencia ascendente y más acelerada en la primera mitad de la década inicial de este siglo, es específicamente relevante en la categoría de 'tejido urbano discontinuo' (...) que ha terminado por imponerse como patrón de ocupación de suelo, superando en superficie al tejido urbano continuo o compacto" (OSE, 2010, p. 320).

La intensidad de este proceso de inundación del territorio con usos y actividades urbanas queda magistralmente reflejada por el geógrafo catalán Oriol Nel.lo (2012), cuando afirma que "en el quinquenio 2000-2005, el período central de lo que algunos denominaron la década prodigiosa del urbanismo español, el volumen anual medio de suelo artificializado subió hasta las 27.666 hectáreas, es decir, 75,80 hectáreas al día, más de 3 hectáreas cada hora. Esto representa que cada 10 días, durante 5 años, se ha artificializado en este nuestro país un ámbito tan extenso como el Ensanche de Barcelona. Un ensanche cada 10 días durante 5 años” (p. 25).

Como consecuencia de esta explosiva velocidad urbanizadora, entre 1996 y 2006 el incremento experimentado por la superficie artificial urbana "equivale a una tercera parte de todo el espacio construido a lo largo de la historia” (Méndez, 2017, p. 16). Ello ha provocado un aumento exponencial de la huella ecológica española, cuyo "ritmo medio de crecimiento diario entre 1995 y 2005 fue de 2,7 metros cuadrados por persona, equivalente a la superficie de 12.000 campos de fútbol” (Gobierno de Espańa, 2008, p. 31). En 2005, el valor de este indicador se situaba en 6,4 hectáreas per cápita, 3,6 veces superior a la biocapacidad mundial (1,78 hectáreas per cápita).

La gravedad de la situación generada por el urbanismo expansivo de esta "década prodigiosa" se acrecienta, si cabe, al heredar todos los desmanes de las burbujas inmobiliarias anteriores, especialmente virulentos en el tardofranquismo. En este periodo comenzó la desorganización entrópica de las periferias de las ciudades españolas y se inició la depredación de nuestro principal recurso territorial, el litoral, soporte geográfico imprescindible para el desarrollo del turismo, actividad económica que, desde mediados del siglo xx, ha desarrollado un rol salvífico para el país. Así, al explotar la última burbuja inmobiliaria, el 34\% del primer kilómetro del litoral mediterráneo se encontraba ocupado por superficies artificiales (OSE, 2014).

Finalmente, hay que destacar la senda economicista emprendida por las políticas públicas de vivienda anudadas a la deriva neoliberal del urbanismo español, que ha orillado a la práctica irrelevancia su dimensión socialmente cohesiva. En concreto, en este periodo, la promoción de vivienda social cayó hasta mínimos históricos (Méndez, Abad \& Echaves, 2015, p. 62), ${ }^{6}$ haciendo aún más difícil el acceso a la

6 En el conjunto de la uE, las menores tasas de vivienda social se registran en Espańa, donde, del total de viviendas nuevas producidas en este periodo, solo el 10,6\% tuvo algún tipo de protección. 
misma de importantes colectivos de nuestra población (Rodríguez, 2015). Y ello pese a que la construcción residencial alcanzó cotas desconocidas hasta entonces, toda vez que durante los años del boom inmobiliario se construyeron algo más de cinco millones de viviendas, a un ritmo de casi dos nuevas viviendas por cada nuevo hogar (Vinuesa, 2013, p. 42). Esta sobreproducción de vivienda asociada al desbocado crecimiento urbanístico de este periodo, ha generado un problema social de incalculables consecuencias que precisa de una solución urgente al constatarse la confluencia perversa de un enorme stock de viviendas sin uso-desocupadas o a medio construir-y de personas sin vivienda (Palacios \& Vinuesa, 2010).

A pesar de las innumerables voces que trataron de justificar esta problemática socioterritorial en la inhibición de todo marco regulador subyacente al urbanismo neoliberal, lo cierto es que la entidad territorial resultante de este esquilmante proceso de urbanización dispersiva es producto de una maniobra política consciente, en la que el planeamiento urbano ha jugado un papel clave como instrumento imprescindible para concretar en el territorio todas las desmesuras congénitas a esta estrategia operacional.

El abandono de criterios de eficiencia funcional, sostenibilidad ambiental y cohesión social en la elaboración del planeamiento urbanístico de este periodo ha permitido su trasmutación en un eficaz instrumento para vehicular la voracidad desmedida e insaciable del mercado inmobiliario (Roch, 2001). "Una versión tergiversada del urbanismo que ha convertido la vivienda en un negocio proclive a la especulación y generador de unas enormes plusvalías" (Vinuesa, 2013, pp. 103-104).

En definitiva, la ciudad heredada de la última burbuja inmobiliaria responde a un modelo urbano-territorial expresivo de las estrategias de ordenación instrumentadas por un tipo de planeamiento urbano caracterizado -salvando honrosas excepciones- por un excesivo énfasis tecnocrático-burocrático que ha favorecido su plegamiento a los intereses del sector inmobiliario: (i) laxitud en sus objetivos y directrices; (ii) fomento de la dispersión territorial con actuaciones urbanísticas anoréxicas (bajas densidades y desnutrición funcional); (iii) prevalencia de las cuestiones técnico-instrumentales en detrimento de la calidad del proyecto de ciudad; y (iv) "urbanismo concesional" (Gaja i Díaz, 2015), que otorga el protagonismo en la toma de decisiones sobre los modelos de ciudad a la iniciativa privada y fomenta su liderazgo en la ejecución urbanística.

\section{La condescendencia de la sociedad española con las políticas neoliberales de la "década prodigiosa"}

Uno de los grandes contrasentidos, incongruencias o sinrazones del periodo histórico analizado es que, mientras el país se encaminaba irremediablemente a la dramática situación causada por el súbito derrumbe de este ciclo alcista, la sociedad

7 Esta sección está extraída del apartado 4.1.3. de un artículo monográfico titulado "Burbujas inmobiliarias y planeamiento en España: 'una amistad peligrosa' ”, publicado en el número 111 de la revista Cuadernos de Investigación Urbanística, editada por el Instituto Juan de Herrera de la Universidad Politécnica de Madrid. Las reflexiones vertidas en dicho apartado han sido reanalizadas, depuradas, clarificadas y reformuladas en el presente artículo. 
española fue condescendiente con esta suerte de "desastre anunciado", manifestando una actitud tolerante y receptiva con las políticas de corte neoliberal impulsadas por los diferentes niveles de gobierno (estatal, regional y local). Es decir, la sociedad española, durante la "década prodigiosa" de la última burbuja inmobiliaria, ha estado afectada por una "ceguera moral colectiva" que le ha impedido desarrollar los anticuerpos necesarios para combatir los efectos patógenos de las políticas antes enunciadas.

La reflexión realizada en el presente epígrafe se estructura sobre tres ensayos del recientemente fallecido sociólogo polaco Zygmunt Bauman: La modernidad líquida (2004), Confianza y temor en la ciudad. Vivir con extranjeros (2006) y La ceguera moral (2015), compartido este último con el politólogo lituano Leonidas Donskis. A partir de la visualización de las principales características definitorias del proceso de disolución de las categorías sociológicas representativas de la primera modernidad -rutinización de conductas sociales, racionalidad instrumental, comunión pacífica entre capital y trabajo, estabilidad biográfica, confianza en el futuro prefigurado por la acción colectiva- se pretende esbozar los perfiles que dibujan el rostro de una sociedad que aceptó acríticamente las tesis socioeconómicas de corte neoliberal imperantes en aquellos años ${ }^{8}$ que, cabalgando a lomos de una frenética actividad constructora, encumbraron el mercado inmobiliario a una posición dominante, privilegiada y referencial.

Así, el discurso se centra en entablar un diálogo entre epifenómenos determinantes de la modernidad líquida (la dilapidación de la procrastinación, el comunitarismo líquido y la adiaforización) y tres aspectos relevantes de la conducta social en aquellos años: (i) la deslegitimación generalizada del planeamiento urbano como ejercicio colectivo para configurar un futuro urbano expresivo del interés general de la ciudadanía; (ii) la preferencia social por un modelo territorial difuso, licuado y fragmentado, que se ha mostrado especialmente idóneo para acomodar las tendencias mixofóbicas que caracterizan una sociedad extremadamente individualizada; y (iii) el consentimiento de actitudes y comportamientos éticamente reprobables alentados por el "empresarialismo urbano" antes reseńado.

a. La primera modernidad, la época de lo que Bauman (2004) llama el "capitalismo pesado" (p. 61), tuvo como principal paradigma un modelo productivo organizado de manera reglada, rutinaria, jerárquica y eficiente, siendo sus características representativas la racionalidad instrumental y la comunión entre trabajo y capital asociada a un territorio concreto: el Estado-nación. En estas circunstancias históricas aprovisionadoras de seguridad vital, el hombre moderno era capaz de postergar la gratificación a sus esfuerzos, aplazar la satisfacción a un tiempo futuro. En palabras del mismo Bauman, "bajo la forma de la postergación de la gratificación, la procrastinación ${ }^{9}$ puso la inversión por encima de la Rodríguez, 2013, pp. 25-75), modelo de acumulación capitalista que se produce cuando la "plusvalía generada por la urbanización es superior a la de la industrialización”.

9 Según la definición de Bauman (2004), "Procrastinar es situar algo entre las cosas que pertenecen al mañana. (...) la procrastinación deriva su significado moderno del tiempo vivido como peregrinaje, como movimiento de acercamiento a un blanco" (p. 166). 
toma de ganancias, el ahorro por encima del gasto y el trabajo por encima del consumo" (p. 168). Es decir, todo lo contrario de lo que sucede en la actualidad, época caracterizada por el imperio del cortoplacismo y la voracidad consumista compulsiva -también de suelo, también de territorio, si ello comporta beneficios instantáneos- como garante de una satisfacción inmediata. Bauman vincula el concepto sociológico de procrastinación con el tránsito desde una sociedad de productores, a la sociedad de consumidores característica de la condición fluida de la nueva modernidad: "si la ética del trabajo propugnaba la indefinida postergación de la gratificación, la estética del consumo promueve su abolición” (p. 169).

Las características definitorias de la primera modernidad tienen su correlato en el campo urbanístico representado por un tipo de planeamiento urbano de corte positivista, vinculado a las certezas proporcionadas por un conocimiento científico de la "naturaleza de lo urbano" del que era posible deducir, predecir, un modelo territorial óptimamente concebido. Una suerte de planeamiento taylorista, mecanizado y sistematizado. Esta capacidad predictiva del planeamiento urbano de la primera modernidad expresaba un sentir social asociado a la confianza en el futuro que muestra el hombre de este periodo ante la seguridad, la certeza, el convencimiento de que la acción colectiva lo está conduciendo a un porvenir indudablemente mejor.

Por ello, en cierto modo, el planeamiento urbano es un "ejercicio de procrastinación", toda vez que trata de definir voluntariamente un futuro para la ciudad orientado por unos objetivos políticos que se entienden representativos del sentir de la ciudadanía. Y este futuro ha de concebirse como una meta que guíe las estrategias destinadas a configurar el modelo de ciudad ideado. Es decir, la importancia del porvenir urbano-territorial expresado en el planeamiento no es tanto que este sea asible, realizable, sino que defina una ética de comportamiento urbanístico de la que devenga un "saber hacer" enfocado a un horizonte imaginado colectivamente. De este modo, más que la materialización del modelo territorial, es el proceso, el tránsito, la ruta emprendida para lograr culminarlo, el que debe asumir un rol protagónico. De ahí que, en el planeamiento urbano, el largo plazo sea su consustancial temporalidad.

Precisamente, la estabilidad temporal del modelo territorial prefigurado en el planeamiento urbano de la primera modernidad ha sido la razón principal de su cuestionamiento y deslegitimación, una vez que irrumpió, a finales del siglo xx, la ideología neoliberal, el complemento idóneo de la modernidad líquida. Sin modelo futuro no hay orden al que plegarse, no hay horizonte de referencia. Es decir, no hay necesidad de plan y, por tanto, se despeja el camino para desarrollar cualquier iniciativa (privada, claro está) vehiculada a través de proyectos materializables a corto plazo y recluidos en la escala manejable de la ejecución programada. Nada de grandes relatos que impiden, o al menos dificultan, adaptarse a la imprevisibilidad e incertidumbre característica de estos tiempos históricos.

b. El estado actual de la sociedad, en palabras de Bauman (2004), "marca el fin del ser humano como ser social” (p. 189). Por ello, una de las disoluciones a las 
que el nuevo tiempo de la modernidad líquida se aplica con denuedo es la desnaturalización, cuando no completa extinción, de la conciencia de clase social. Este abandono del individuo a su propia suerte lo obliga a buscar "soluciones biográficas a contradicciones sistémicas" (Beck, 1998, p. 135) y produce el afloramiento del comunitarismo como una reacción refleja a la incertidumbre y la inseguridad a las que se ve sometido, ya que "el impulso a protegerse de la riesgosa complejidad dentro del refugio de la uniformidad es universal” (Bauman, 2004, p. 169).

La comunidad de la modernidad líquida, de carácter defensivo y autoprotector, promueve la "fosilización de las diferencias mediante la separación y el aislamiento de unos y otros" (Bauman, 2006, p. 56). Para explicar esta tendencia social, Bauman acuńa el concepto de mixofobia, definiéndola como "una reacción previsible y generalizada ante la inconcebible, escalofriante y angustiosa variedad de tipos humanos y costumbres que coexisten en las calles de las ciudades contemporáneas y sus barrios más corrientes. (...) La mixofobia se manifiesta por la tendencia a buscar islas de semejanza e igualdad en medio del mar de la diversidad y diferencia” (Ibíd., pp. 32-33).

No es de extrañar que, a la vista de estas características, haya existido una predisposición generalizada a aceptar los presupuestos disolutivos de la compacidad urbana característicos del urbanismo neoliberal. Con ello, se premia la libertad individual proporcionada por el hábitat disperso -favorecido por la fragmentación de lo urbano en el territorio- y se incentiva la conformación de comunidades cerradas de acceso vigilado, eliminando cualquier atisbo de conflicto entre sus pobladores.

El gran damnificado de esta nueva expresión territorial inhibidora de la interacción social es el espacio público, lugar donde -en su acepción sociológica clásica- los desconocidos coinciden, condensando y compendiando los rasgos característicos de la vida urbana. La evisceración de la función integradora del espacio público constituye la constatación territorial de la acción diluyente de la modernidad líquida: se procede a disolver en la ciudad aquello que integra y vertebra; aquello que compacta y cohesiona, y el resultado es la inundación del territorio por lo urbano; el liderazgo de los no-lugares, de los flujos; la fragmentación del hábitat, la segmentación social, la purificación funcional de cada zona. La ciudad licuada, fluida, diluida, rota, desmembrada, salpicada, dispersa.

Además, este anhelo segregativo es el que, precisamente, alimenta la mixofobia urbana al actuar como una suerte de "profecía autocumplida". En palabras de Daniel Innerarity (2006):

Sin la capacidad unificadora de los espacios urbanos, la distancia es vivida como rechazo y alimenta el sentimiento de no pertenecer a la misma sociedad. Con la actual fragmentación, la ciudad parece haber perdido esa capacidad de dar cuerpo a la sociedad aproximando a sus componentes, mostrando tanto su diversidad como su interdependencia (p. 121).

En la ciudad contemporánea, por tanto, las calles y las plazas han dejado de ser el principal lugar de encuentro. Para tratar de resolver esta problemática 
se precisaría contribuir al afianzamiento de sentimientos mixofílicos mediante "una estrategia urbanística que fuera la antítesis de la actual (...) La creación de numerosos espacios públicos, abiertos y hospitalarios, a los que acudirían de buen grado toda clase de personas y no tendrían reparo en compartir" (Bauman, 2006, p. 38).

Complementariamente a su dimensión defensiva, el comunitarismo líquido se manifiesta incapacitado para producir los vínculos identitarios característicos de la primera modernidad. En estas "comunidades de guardarropa", expresión acuñada por Bauman, se deshacen los lazos de vecindad congénitos a los barrios de la ciudad moderna, construidos desde la solidaridad y la tolerancia entre sus miembros, ya que "su tiempo de vida es breve y se suelen anudar a algún acontecimiento concreto que es el que fundamenta su constitución y cuya finalización y/o desaparición del interés mediático, certifica su defunción” (Bauman, 2004, pp. 210-211). El movimiento social urbano de la primera modernidad, expresivo de sentimientos de pertenencia al barrio e impulsor de reivindicaciones vecinales, se desvanece ante las pulsiones mixofóbicas de estos tiempos líquidos sometidos al imperio del individualismo.

Por ello -volviendo al campo disciplinar del urbanismo- es tan complejo, hoy en día, hablar con certeza y determinación en nombre del interés público, principal argumento legitimador de las políticas urbanas. Máxime si el interés público se decide en la atalaya de los ámbitos ilustrados del conocimiento experto. Por eso, la única vía socialmente aceptable para justificar el planeamiento urbanístico proviene de la vehiculación de las demandas ciudadanas mediante procesos de participación abiertos y transparentes.

No debe extrańar que, ante este hecho, hayan triunfado las tesis del urbanismo neoliberal, ya que, al estallar el interés colectivo en una plétora de intereses particulares -en muchos casos discordantes-, la acción del gobierno de la ciudad se ha visto impelida a arbitrar en estas contradicciones, estableciendo unas reglas básicas de funcionamiento para dejar hacer a la iniciativa privada al entender que, desde su afán lucrativo, adoptará decisiones eficientes que garantizarán el bienestar social.

c. Una de las principales consecuencias de la nueva condición humana resultante de la modernidad líquida es la trasmisión al cuerpo social de una suerte de insensibilidad moral denominada adiaforización, estratagema o argucia empleada "para situar ciertos actos fuera del universo de las obligaciones morales evitando, con ello, la necesidad de someterlos a un juicio ético” (Bauman \& Donskis, 2015, p. 57). El concepto de adiaforización explica, en gran medida, la aceptación social de las políticas sumisas a los requerimientos del mercado, que, además de caracterizar el periodo del último boom inmobiliario, continúan imponiendo su poder durante la fase posterior al estallido de la burbuja.

Esta aceptación tiene diferentes rostros: (i) el austericidio al que nos han sometido las políticas emanadas de la uE y que tan disciplinadamente han sido aplicadas por el gobierno español surgido en plena crisis económica; (ii) el progresivo e indetenible ataque perpetrado al Estado de bienestar con el objetivo, nunca declarado 
abiertamente, de proceder a su privatización (Losada, 2013); (iii) la estrategia de fomentar el enriquecimiento de las clases pudientes como fundamento para mejorar, por destilado capilar, las condiciones de vida del resto de la masa social (Bauman \& Donskis, 2015, pp. 84-85); (iv) el surgimiento de una nueva formación social denominada "precariado", situada "a un paso de la exclusión social y el abismo de la pobreza gracias a las políticas de austeridad y al desmantelamiento del Estado del bienestar" (Standing, 2013); y, cómo no, (v) la política urbanística expansiva, dislocada, consumista de territorio y desprovista de cualquier atadura ética que ha guiado la producción de ciudad en los últimos años.

Pero, sobre todo, la adiaforización -como anomalía del comportamiento socialencuentra su expresión paradigmática en la aceptación de una forma de ejercer el gobierno del territorio trufada de prácticas perversas, de plegamiento a los intereses de la iniciativa privada. Así, la sociedad española llegó a consentir la corrupción urbanística como un suceso inevitable, un mal menor, para garantizar el persistente, permanente y desbocado crecimiento económico.

El escritor Antonio Muñoz Molina se preguntaba, allá por 2013, cómo había sido posible no darse cuenta; cómo a la luz de la información ofrecida en aquellos años, nadie reparó en que tras las cifras de la fiesta se ocultaba, latente, el desastre que finalmente afloró con el estallido de la burbuja (Muñoz, 2013, pp. 155-156). El argumento que esgrime es que el efecto de esas cifras mareantes fue similar al provocado por el fragor de una catarata sobre quienes viven tan cerca de ella que no la escuchan. Este déficit sensitivo estuvo provocado por la insensibilidad moral -la adiaforización- inherente a la disolución de los vínculos sociales experimentada en la modernidad líquida.

\section{¿Hacia una nueva burbuja inmobiliaria? \\ De la condescendencia inmunodeficiente a la reflexividad social, para modificar la tendencia inercial de la historia reciente}

Atendiendo al carácter cíclico de la economía capitalista, cada periodo expansivoinmobiliario acaecido en España a lo largo del último medio siglo ha encadenado su consiguiente hiato recesivo. Tras la repentina deflagración de la última burbuja -la más voraz y territorialmente depredadora de todas-, la depresión causada se ha manifestado especialmente intensa, dolorosa y duradera, ocasionando una retracción económica sin precedentes, una grave precarización social y una importante problemática medioambiental.

Efectivamente, esta burbuja especulativa -que acabó muriendo por estrangulamiento financiero- nos ha legado, por un lado, una situación socioeconómica investida de cierto dramatismo: cifras de paro alarmantes, desaparición del sector empresarial-inmobiliario (Rodríguez, 2015, pp. 4-6), desorbitante déficit estatal (Méndez, Abad \& Echaves, 2015, p. 273), la quiebra de un importante número de entidades crediticias o el empobrecimiento de la clase media. Y, por otro, un problema ambiental, territorial y urbano de enorme magnitud (Burriel, 2014). Estos datos deben alertar del peligro subyacente a que la reactivación económica de España, germinada en el último cuatrienio, vuelva a sustentarse en la actividad inmobiliaria. 
Los indicios existentes apuntan a esta posibilidad, ya que la recuperación de la competitividad de la economía española se está produciendo, básicamente, a caballo de una intensa devaluación salarial, estrategia de política económica cimentada en promover el incremento de la tasa de beneficios empresariales a costa de la precarización laboral. Según datos de la Contabilidad Nacional publicados por el Instituto Nacional de Estadística (INE), la masa salarial total de 2016, en plena fase de reanimación económica, fue 34.000 millones de euros inferior a la existente en 2008, al comienzo de la crisis. En referencia al sector de la construcción (el demiurgo laboral de la burbuja inmobiliaria), la merma se cifra en un 55\%, lo cual explica que la tasa de paro en España presente porcentajes aún muy elevados. ${ }^{10}$

Esta estrategia corre el peligro de provocar una importante declinación del consumo privado, lo cual podría conducir a un nuevo estancamiento económico. Entre las soluciones que se auguran para evitarlo se encuentra la posibilidad de reverberar el endeudamiento de las familias mediante la formación de nuevas burbujas de activos financieros e inmobiliarios, lo que permitiría reactivar el sector de la construcción. El hecho de que tanto el Banco Central Europeo como el Fondo Monetario Internacional hayan alertado de la creación de burbujas en los mercados inmobiliarios de Austria, Bélgica, Dinamarca, Finlandia, Holanda, Luxemburgo, Reino Unido y Suecia, es un dato necesario a tener en cuenta. En Espańa, la precariedad laboral, la devaluación salarial y las políticas de contención del crédito, tanto a particulares como a promotoras, han actuado de muro de contención; "pero, de desaparecer, el mercado podría volver a calentarse demasiado, ya que la administración española no ha tomado medidas para evitar otra burbuja". ${ }^{11}$

No debe sorprendernos esta contingencia. El economista americano John Kenneth Galbraith (1991) alertaba de la extrema brevedad de la memoria de los mercados. Esta actitud olvidadiza se denomina, en lenguaje económico, la "miopía del desastre": cuanto más nos alejamos del mismo, más tendemos a repetirlo. De ser cierta esta afirmación, una vez superada la travesía de la recesión, el capitalismo inmobiliario habrá olvidado su responsabilidad en las causas que nos han llevado a sufrir la crisis más prolongada y tóxica de la historia reciente de España y se encontrará liberado de los remordimientos que lo han tenido hibernando estos ańos. Ello provocará, previsiblemente, el relanzamiento de la actividad inmobiliaria y de la construcción, sectores que han sustanciado los periodos de crecimiento económico que se han sucedido en nuestro país a lo largo del último medio siglo.

Hay datos que parecen confirmar este pronóstico. Así, el número de hipotecas formalizadas para compra de vivienda en el año 2017 (310.096) fue el más alto desde 2011 y su importe medio (116.709 euros) experimentó un 6,3\% de incremento interanual (INE, 2018, p. 43). En estos años de resurgimiento económico, el precio de la vivienda ha subido siete veces más que el salario medio, y en el tercer trimestre del año 2017 experimentó el mayor ritmo de crecimiento de la última

10 La tasa de paro en el segundo trimestre de 2018 fue del 15,28\% (INE, Encuesta de Población Activa).

11 “La burbuja inmobiliaria acecha a España”, por S. López Letón, El País, 27 de marzo de 2017. https://elpais.com/economia/2107/03/24/actualidad/1490367506_170978.htm 
década (INe, Índice de Precio de la Vivienda). Por último, resulta muy sintomático que, en el primer trimestre de 2018, el sector de la construcción haya crecido al $6 \%$ de tasa interanual -la mayor desde 2001-, duplicando la del conjunto del PIB español (Ine, Contabilidad Nacional Trimestral).

Existen, por tanto, vestigios que revelan la posible incubación de una nueva burbuja inmobiliaria. En esta dirección apuntan opiniones como la del economista Julio Rodríguez, expresidente del Banco Hipotecario de España. En concreto, este experto confirmó, en una comparecencia reciente en el Congreso de los Diputados, el riesgo de dicha incubación, con la diferencia de que "quienes en este momento están aportando más dinero en España no están siendo los bancos, sino los fondos de inversión; son fondos extranjeros los que están comprando suelo e incluso construyendo como promotores" (Congreso de los Diputados, 2017, p. 61).

¿Nos encontramos en los estertores del prolongado ciclo del capitalismo inmobiliario español o, más bien, estamos comenzando a escribir un nuevo capítulo de una historia interminable? Este es uno de los grandes dilemas que debemos dilucidar a corto plazo. Habrá que esperar acontecimientos, pero no parece aventurado vaticinar que, con la hoja de ruta emprendida, va a resultar muy complejo salir del bucle generado por la sucesión de periodos económicos expansivos y depresiones profundas, vinculados al protagonismo de la actividad inmobiliaria y el sector de la construcción (López \& Rodríguez, 2010, pp. 206-207). Sin embargo, reconducir esta tendencia inercial característica del modelo socioeconómico español, ha de constituirse en el principal propósito del rumbo a emprender por una nueva senda política imaginativa, experimental e innovadora que consiga hacer de Espańa un territorio más "resiliente que reincidente".

El concepto de "resiliencia territorial" nos informa, precisamente, de la "capacidad de reacción que muestran algunos lugares ante situaciones adversas generadas por periodos depresivos que ponen en cuestión su funcionalidad anterior" (Méndez, 2012, p. 219). Pero la resiliencia no es una cualidad congénita de los territorios, sino una construcción social (Méndez, 2013, p. 16) que requiere desarrollar "tácticas de choque de la imaginación, que desplacen el sentido común existente sedimentado y que abran la posibilidad a otras maneras de pensar" (Massey, 2012, p. 249). Para ello -entre otros factores, tales como contar con un idóneo capital productivo, financiero e institucional-, se precisa de un capital humano dotado con una capacitación formativa de la que, lamentablemente, adolece la población adulta espańola en la actualidad (Ministerio de Educación, Cultura y Deporte, 2016, pp. 7-9). ${ }^{12}$ Además, no parece que el futuro inmediato apunte a un cambio sustancial de esta precaria situación, toda vez que, en 2016, la tasa de abandono escolar temprano en España, cercana al 20\%, duplicaba la de la Ue-28 (INE, Encuesta de Población Activa).

Este déficit formativo puede lastrar la capacidad transformacional de la sociedad española, al dificultar el desarrollo del pensamiento crítico (Marina, 2012) que se

12 El porcentaje de población adulta española con estudios inferiores a la segunda etapa de Secundaria es del $43 \%$, frente al $23 \%$ existente en la Organización para la Cooperación y el Desarrollo Económicos (ocDE) o el $21 \%$ de la UE-22. Pero, sin duda, el dato más significativo es que el $34,4 \%$ de los adultos jóvenes españoles (25-34 años) no han completado este nivel educativo, frente al $16,4 \%$ de la ocDe y el $14,9 \%$ de la UE- 22 . 
necesita para enmendar las políticas neoliberales desplegadas años atrás, con especial énfasis en aquellas de dimensión urbano-territorial, ante la indigerible herencia recibida de los excesos cometidos y sus pavorosas repercusiones socioambientales. Este legado -más allá de la "destrucción creativa" de los espacios centrales y subcentrales de la ciudad en que deviene la gentrificación de su cuerpo social- presenta un rostro inequívocamente específico y característico (Sevilla, 2015): una vertiginosa artificialización de territorio, conformadora de una suburbanización bulímica y expansiva que ha licuado la tradicional condición compacta de la ciudad española. El sobredimensionado capital físico transmitido ha llegado, indudablemente, para quedarse; es decir, "constituirá una herencia con la que nosotros y las generaciones venideras deberemos inevitablemente lidiar durante largas décadas. Toda pretensión de negar esta realidad, de desconocerla o erradicarla no puede ser otra cosa que escapismo o quimera" (Nel.lo, 2012, p. 29).

La reconducción reclamada párrafos atrás debería, por consiguiente, evitar perseverar en el bussiness as usual del sector inmobiliario, parapetando su impulsiva voracidad con un urbanismo regenerativo que aporte racionalidad y sensatez a esta desmesura consumista de territorio. Sin embargo, las políticas territoriales de nuestras administraciones públicas, desnortadas y sin rumbo aparente, han transitado desde el "dejar hacer" efervescente de los años del "tsunami urbanizador" (Fernández, 2006), al "no saber qué hacer" de los años de recesión. Reactivar su capacidad de respuesta para reorientar, desde nuevos presupuestos oxigenados, el planeamiento urbano de la época poscrisis resulta trascendental (Górgolas, 2016). Y esta maniobra terapéutica precisa del respaldo de la sociedad española, que deberá experimentar una metamorfosis radical de su comportamiento ante las cuestiones territoriales para, desde la reflexividad, embridar el discurso economicista dominante con ataduras éticas que prevengan de la tendencia a reincidir en errores pasados.

En conclusión, hay que suscitar el reforzamiento del sistema inmunitario de la sociedad española ante el augurio de reproducción de un nuevo ciclo expansivo dominado por políticas similares a las desencadenantes de la "década prodigiosa". Porque, como se ha constatado en el presente artículo, la ideología neoliberal competitivamente desigual, insolidaria e incentivadora del individualismo y la desregulación de la acción pública-, lejos de fomentar la resiliencia de los territorios aumenta su vulnerabilidad, especialmente en aquellos, como el español, que "optaron por modelos de crecimiento excesivamente especializados en lo económico, polarizados en lo social e insostenibles en lo ambiental” (Méndez, 2013, p. 16).

\section{Referencias bibliográficas}

Bauman, Z. (2004). Modernidad líquida. Buenos Aires: Fondo de Cultura Económica.

Bauman, Z. (2006). Confianza y temor en la ciudad. Vivir con extranjeros. Barcelona: Arcadia. Bauman, Z \& Donskis, L. (2015). Ceguera moral. La pérdida de sensibilidad en la modernidad líquida. Barcelona: Paidós.

Beck, U. (1998). La sociedad del riesgo: hacia una nueva modernidad. Barcelona: Paidós. 
Burriel, E. (2014). El estallido de la burbuja inmobiliaria y sus efectos en el territorio. En J. M. Albertos Puebla \& J. L. Sánchez Hernández (coords.), Geografía de la crisis económica en España. Valencia: Universidad de Valencia.

Campos, J. L. (2008). La burbuja inmobiliaria española. Madrid: Marcial Pons.

Congreso de los Diputados. (2017). Diario de Sesiones. Comisiones de Investigación. XII Legislatura. Número 12.

Daher, A. (2013). El sector inmobiliario y las crisis económicas. EURE, 39(118), 47-76. http:// dx.doi.org/10.4067/S0250-71612013000300003

Fernández, R. (2006). El tsunami urbanizador español y mundial: sobre sus causas y repercusiones devastadoras, y la necesidad de prepararse para el previsible estallido de la burbuja inmobiliaria. Barcelona: Virus Editorial.

Gaja i Díaz, F. (2015). Urbanismo concesional. Modernización, privatización y cambio de hegemonía en la acción urbana. Ciudades, (18), 103-126. https://doi.org/10.24197/ ciudades.18.2015.103-126

Galbraith, J. K. (1991). Breve historia de la euforia financiera. Barcelona: Ariel.

García-Montalvo, J. (2008). De la quimera inmobiliaria al colapso financiero. Crónica de un desenlace anunciado. Barcelona: Antoni Bosch Editor.

García-Montalvo, J. (2009). Financiación inmobiliaria, burbuja crediticia y crisis financiera. Lecciones a partir de la recesión de 2008-09. Papeles de Economía Española, (122), 6687. https://bit.ly/2Q6qYUV

Gobierno de España, Ministerio de Medio Ambiente, y Medio Rural y Marino (2008). Análisis de la huella ecológica en España. Madrid: Centro de Publicaciones, Secretaría General Técnica, Ministerio de Medio Ambiente, y Medio Rural y Marino. https:// bit.ly/2rTnlb9

Górgolas, P. (2016). La planificación de la ciudad en el cambio de milenio (1997-2017). Propuestas para reconducir la herencia recibida: los casos de Casares (Málaga) y Chiclana de la Frontera (Cádiz). Tesis Doctoral, Departamento de Urbanística y Ordenación del Territorio de la Universidad de Sevilla. https://idus.us.es/xmlui/handle/11441/52364

Górgolas, P. (2017). Burbujas inmobiliarias y planeamiento urbano en España: una amistad peligrosa. Cuadernos de Investigación Urbanística no 111 . Instituto Juan de Herrera. Universidad Politécnica de Madrid. https://doi.org/10.20868/ciur.2017.111.3536

Instituto Nacional de Estadística (INE) (2018). España en cifras, 2018. Madrid: INE. Catálogo de publicaciones oficiales de la Administración General del Estado. https://bit. ly/2wTbWuD

Innerarity, D. (2006). El nuevo espacio público. Madrid: Espasa Calpe.

Logan, J. R \& Molotch, H. (2015). La ciudad como máquina de crecimiento. En Observatorio Metropolitano de Madrid (eds.), El mercado contra la ciudad. Globalización, gentrificación y políticas urbanas (pp. 157-210). Madrid: Traficantes de Sueños.

López de Lucio, R. (1997). Planeamiento urbanístico. Mercado del suelo y políticas del suelo. Bases para el debate sobre la reforma de la legislación urbanística en España. Urban (1), 79-90. http://polired.upm.es/index.php/urban/article/view/174

López, I. \& Rodríguez, E. (2010) Fin de ciclo. Financiarización, territorio y sociedad en la onda larga del capitalismo hispano (1959-2010). Madrid: Traficantes de Sueńos.

López I. \& Rodríguez, E. (2011). The Spanish Model. New Left Review, (69), 5-29. https:// newleftreview.org/II/69/isidro-lopez-emmanuel-rodriguez-the-spanish-model 
López I. \& Rodríguez, E. (2013). Competitividad territorial y circuito secundario de acumulación. El paroxismo de un caso: el ciclo español de 1995-2007. En Observatorio Metropolitano de Madrid (eds.), Paisajes devastados. Después del ciclo inmobiliario: impactos regionales y urbanos de la crisis (pp. 25-75). Madrid: Traficantes de Sueños.

Losada, A. (2013). Piratas de lo público. El neoliberalismo corsario al abordaje del Estado del Bienestar. Una defensa sin complejos del sistema público. Bilbao: Ediciones Deusto.

Marina, J. A. (2012). Síndrome de Inmunodeficiencia Social. El Mundo, 25 de marzo de 2012. http://www.joseantoniomarina.net/articulo/sindrome-de-inmunodeficiencia-social/

Massey, D. (2012). Londres, diciembre de 2011. En A. Albert \& N. Benach (eds.), Doreen Massey. Un sentido global del lugar (pp. 247-264). Barcelona: Icaria.

Mella, J. M. (2008). "Explosión de la ciudad" y ordenación del territorio en España: algunos apuntes. Clm Economia: Revista económica de Castilla-La Mancha, (11), 65-199. http:// www.clmeconomia.jccm.es/pdfclm/mella_11.pdf

Méndez, R. (2012). Ciudades y metáforas: sobre el concepto de resiliencia urbana. Ciudad y Territorio. Estudios territoriales, (172), 215-231. https://www.eukn.eu/fileadmin/Lib/ files/ES/2013/01-CyTET\%20172.pdf

Méndez, R. (2013). Estrategias de desarrollo territorial para tiempos de crisis. Una interpretación desde la periferia europea. Desenvolvimento Regional em debate, 3(2), 4-26. https://doi. org/10.24302/drd.v3i2.463

Méndez, R. (2014). Expansión y crisis del modelo neoliberal en Madrid. En R. Hidalgo \& M. Janoschka (eds.), La ciudad neoliberal (pp. 217-232). Santiago: Pontificia Universidad Católica de Chile.

Méndez, R (2017). De la hipoteca al desahucio: ejecuciones hipotecarias y vulnerabilidad territorial en España. Revista de geografía Norte Grande, (67), 9-31. http://dx.doi. org/10.4067/S0718-34022017000200002

Méndez, R., Abad, L. D. \& Echaves, C. (2015). Atlas de la crisis. Impactos socioeconómicos y territorios vulnerables en España. Valencia: Tirant Humanidades.

Ministerio de Educación, Cultura y Deporte (MECD), España. (2016). Panorama de la Educación. Indicadores de la ocde, 2016. Informe Español. Madrid: MECD. https://bit.ly/2cdjBMj

Muñoz Molina, A. (2013). Todo lo que era sólido. Barcelona: Seix Barral.

Naredo, J. M. \& Montiel, A. (2011). El modelo inmobiliario español y su culminación en el caso valenciano. Barcelona: Icaria.

Nel.lo, O. (2012). Herencias territoriales, exploraciones geográficas y designios políticos. En J. Schulz-Dornburg, R. Argullol, P. Azara Nicolás, O. Nel·lo \& J. Puntí, Ruinas modernas. Una topografía del lucro (pp. 23-69). Barcelona: Ambit. Servicios Editoriales. Colección Palabra y Paisaje.

Observatorio de la Sostenibilidad en España (OSE) (2010). Sostenibilidad en España 2010. Madrid: ose.

Observatorio de la Sostenibilidad en España (OSE) (2014). Sostenibilidad en España 2014. Madrid: ose.

Palacios, A \& Vinuesa, J. (2010). Un análisis cualitativo sobre la política de vivienda en España. La opinión de los expertos. Anales de Geografía, 30(1), 101-118. http://revistas.ucm. es/index.php/AGUC/article/view/AGUC1010120101A/30740

Roch, F. (2001). Hegemonía inmobiliaria y desregulación urbanística. El declive del Plan Creador. Urban, (6), 6-14. http://polired.upm.es/index.php/urban/article/view/322 
Rodríguez, J. (2006). Los booms inmobiliarios en España. Un análisis de tres períodos. Papeles de Economía Española, (109), 76-90.

Rodríguez, J. (2015). Observatorio de vivienda y suelo. Boletín Anual 2014. Madrid: Ministerio de Fomento, Gobierno de Espańa. https://bit.ly/2BEO8MS

Rodríguez, J. (2017). Las viviendas que pudieron hundir la economía. La caída del mercado de vivienda y sus consecuencias. Cuadernos de Relaciones Laborales, 35(1), 71-99. http:// revistas.ucm.es/index.php/CRLA/article/view/54984/0

Sevilla, A. (2015). Urbanismo, crisis y austeridad. Ciudades, (18), 31-48. http://oa.upm. es/41007/

Standing, G. (2013). El Precariado. Barcelona: Pasado y Presente.

Theodore, N. Peck, J \& Brenner, N (2009, marzo). Urbanismo neoliberal: la ciudad y el imperio de los mercados. Temas Sociales, (66). Santiago: SUR Corporación de Estudios Sociales y Educación. http://www.sitiosur.cl/r.php?id=898

Torres, J. (2010). La crisis de las hipotecas basura. ¿Por qué se cayó todo y no se ha hundido nada? Madrid: Ediciones Sequitur.

Vásquez Rocca, A. (2008). Zygmunt Bauman: modernidad líquida y fragilidad humana. Nómadas. Revista Crítica de Ciencias Sociales y Jurídicas, 19(3), 309-316. https://www. redalyc.org/articulo.oa?id= 18101917

Vinuesa, J. (2013). El festín de la vivienda. Auge y caída del negocio inmobiliario en España. Madrid: Díaz \& Pons. 